\title{
Clinical diagnosis of current asthma: predictive value of respiratory symptoms in the SAPALDIA study
}

\author{
D. Sistek*, J-M. Tschopp*, C. Schindler\#, M. Brutsche*, U. Ackermann-Liebrich" \\ A-P. Perruchoud ${ }^{*}$, P. Leuenberger ${ }^{+}$and SAPALDIA team ${ }^{+}$
}

Clinical diagnosis of current asthma: Predictive value of respiratory symptoms in the SAPALDIA study. D. Sistek, J-M. Tschopp, C. Schindler, M. Brutsche, U. Ackermann-Liebrich, A-P. Perruchoud, P. Leuenberger and SAPALDIA team. (C) ERS Journals Ltd 2001.

ABSTRACT: Bronchial asthma is a very common disease which often remains underdiagnosed. The aim of this study was to determine the predictive value of the most common respiratory symptoms and to explore the best symptom combinations to predict diagnosis of asthma.

A questionnaire comprising common respiratory symptoms was submitted to 9,651 subjects aged 18-60 yrs, randomly selected from the Swiss population, of whom 225 subjects $(2.3 \%)$ had current asthma as confirmed by their general practitioner. Based on these data the authors calculated the predictive values of single symptoms and symptom combinations to diagnose asthma.

Wheezing was the most sensitive single symptom (sensitivity $75 \%$ ). Simple symptoms such as wheezing with dyspnoea, chronic phlegm or chronic cough had specificity greater than 95\%. Wheezing with dyspnoea (WD) or nocturnal dyspnoea (ND) had the best positive predictive value (PPV) as isolated symptoms $(24 \%$ and $21 \%$, respectively). When combining symptoms, wheezing associated with daily dyspnoea at rest or nocturnal dyspnoea showed the best PPV (42\% and 39\%, respectively), almost double single symptoms such as WD or ND. Wheezing associated with at least two of the three nocturnal symptoms (nocturnal dyspnoea, nocturnal cough or nocturnal chest tightness) had a sensitivity of $80 \%$ to diagnose asthma.

In conclusion, respiratory symptoms obtained by medical history are reliable predictors of asthma. The findings suggest that particular combinations of symptoms are clinically useful in the differential diagnosis of asthma.

Eur Respir J 2001; 17: 214-219.

\begin{abstract}
*Centre Valaisan de Pneumologie Montana, Suisse, ${ }^{\#}$ Institut de Médecine Sociale et Préventive Bâle, Suisse, 'Dept de Médecine Interne, Hôpital Universitaire de Bâle, Bâle, Suisse and ${ }^{+}$Division de Pneumologie, Centre Hospitalier Universitaire Vaudois, Lausanne, Suisse.
\end{abstract}

Correspondence: Dr J. Tschopp PD Centre Valaisan de Pneumologie, 3962 Montana, Suisse. Fax: 41276038181

Keywords: Asthma

diagnostic sensitivity and specificity positive and negative predictive value prevalence

respiratory symptoms

Received: January 42000

Accepted after revision September 4 2000
Asthma is a common respiratory disease which affects more than $5 \%$ of the Swiss population [1]. The prevalence of asthma varies considerably among studies due to the lack of well accepted definitions [2] and the different clinical or epidemiological approaches, and underlying population characteristics. Asthma can present with a broad variety of symptoms. Chronic cough may be the sole presenting symptom of asthma [3-5]. The classical triad of dyspnoea, cough and wheezing does not have a sufficient predictive value to diagnose asthma. BAUMANN et al. [6] showed that only $36 \%$ of asthmatics have these three symptoms simultaneously. Isolated symptoms, such as wheezing or dyspnoea, have been shown to be better predictors of asthma. In a longitudinal study of more than 1,000 subjects, Burrows et al. [7] showed that wheezing was the predominant symptom in recently diagnosed asthma. A European study based on the European Respiratory Survey confirmed the strong correlation between asthma and wheezing or nocturnal dyspnoea (relative risk of $29 \%$ and $26 \%$, respectively). The correlation with chest tightness and nocturnal cough was weaker (relative risk of $13 \%$ and $3 \%$, respectively) [8]. To the authors' knowledge, no study has previously looked for the best symptom or combination of symptoms that would enable any general practitioner to reliably diagnose bronchial asthma through medical history.

The aim of this study was to determine the diagnostic value of isolated respiratory symptoms in a large cohort of asthma patients drawn from the general population, and to find combinations of symptoms with the best predictive value for the diagnosis of bronchial asthma.

\section{Materials and methods}

The data were collected from the SAPALDIA (Swiss Study on Air Pollution and Lung Diseases in Adults) study, a project financed by the Swiss National Research Foundation [9].

\section{Patients}

Out of 17,500 subjects (aged 18-60 yrs), randomly selected from eight Swiss areas 9,651 (59\%) participated 
in the study and correctly replied to a standardized and computerized questionnaire on respiratory symptoms. It was based on the questionnaire of the European Community Respiratory Health Survey and used in three languages (German, Italian and French) depending on the investigated area. There were no significant differences in the demographic data (age, race, sex, social status) between the subjects who participated and those who refused to participate [9]. The cohort studied was therefore representative of the selected population.

\section{Respiratory symptoms}

The following questions were asked, relating to different symptoms: 1. Wheezing (W): Have you had wheezing or whistling in your chest at any time in the last 12 months? 2. Wheezing with dyspnoea (WD): Have you been breathless when the wheezing noise was present the last 12 months? 3. Wheezing without cold (WwC): Have you had this wheezing or whistling during the last 12 months when you did not have a cold? 4. Nocturnal chest tightness (NCT): Have you woke up with a feeling of tightness in your chest at any time in the last 12 months? 5. Rest dyspnoea (RD): Have you had an attack of shortness of breath when you were at rest at any time in the last 12 months? 6 . Exercise dyspnoea (ED): Have you had an attack of shortness of breath that came on following strenuous activity at any time in the last 12 months? 7 . Nocturnal cough (NC): Have you been woken up by your coughing at any time in the last 12 months? 8 . Nocturnal dyspnoea (ND): Have you ever been woken up by an attack of shortness of breath at any time in the last 12 months? 9. Chronic cough (CC): Do you usually cough during the day or at night in the winter, i.e., do you usually cough during the day or at night, on most days for as much as 3 months each year over at least 2 years? 10. Chronic phlegm (CP): Do you usually bring up any phlegm from your chest during the day or at night in the winter, i.e., do you usually bring up any phlegm from your chest during the day or at night, on most days for as much as 3 months each year over at least 2 years? Chronic bronchitis (CB) corresponds to chronic cough and phlegm.

\section{Definitions of asthma}

Current asthma was defined by positive responses to each of the following questions: 1 . Do you have or have you ever had asthma? 2. Was asthma confirmed by a medical practitioner? 3. Have you ever had at least one asthma attack during the last 12 months? Asthma was defined as positive responses to the first two questions only. Only subjects with current asthma were considered for this study.

\section{Analysis}

All answers to the questionnaire were entered into a computer database by specifically trained staff. Statis- tical analyses were performed with the SAS program [9].

\section{Definition of diagnostic predictor}

These indices were calculated according to GRENIER [10] and WeInSTEIn [11]. A predictor may be a clinical test, a symptom or a combination of symptoms. Sensitivity $(\mathrm{S})$ is the frequency of positive predictor values among subjects with the disease. Specificity (SP) is the frequency of negative predictor values among subjects without the disease. The positive predictive value (PPV) is the probability that a subject has the disease when the predictor is positive. The negative predictive value (NPV) is the probability that a subject does not have the disease when this predictor is negative. The Youden index $(\mathrm{J})$ evaluates the diagnostic efficacy of a test. It is expressed as $\mathrm{J}=(\mathrm{S}+\mathrm{SP})-1$. If the index is equal or below 0 , the diagnostic efficacy of the test is poor. On the other hand, the closer it is to 1, the higher is its diagnostic value.

\section{Search for the best combinations of symptoms}

The best combinations of symptoms to predict the diagnosis of asthma were found according to the following method:

Step 1: All the possible combinations of the 11 individual symptoms were investigated. A yes or no answer to each question gives $2^{11}$, i.e. 2,048 different combinations of individual symptoms. Among these possibilities, the authors only selected combinations which included at least $50 \%$ of asthmatics. This reduced the number of combinations to 51. Step 2: Of the asthmatics showing one of the 51 selected combinations, the authors calculated the prevalence of each of the 11 symptoms. The single symptoms with the highest prevalence were thus the most predictive for asthma in these combinations of symptoms. Step 3: A certain number of asthmatics $(57 / 225,25 \%)$ did not have any wheezing, the most prevalent symptom. Therefore, it was crucial to identify the most common symptom among these asthmatics. Using the same method as described in step 2, the authors looked for the prevalence of each of the eight remaining symptoms among the combinations of individual symptoms which do not include the three types of wheezing (W, WD, WwC) in nonwheezer asthmatics. This analysis gave us the prevalence of the most frequent symptoms among subjects with current asthma who had no wheezing at all in the last 12 months. Step 4: Combinations of symptoms were constructed from the individual symptoms selected in steps 2 and 3, and their value as a predictor was calculated.

\section{Results}

Two-hundred and twenty-five subjects (2.3\%) suffered from current asthma at the time of the study, and were therefore included. Out of the initial population of 9,651 subjects, $1,360(14 \%)$ reported 
Table 1.-Diagnostic value of isolated symptoms

\begin{tabular}{lccccc}
\hline Symptom & $\mathrm{S} \%$ & $\mathrm{SP} \%$ & $\mathrm{PPV} \%$ & $\mathrm{NPV} \%$ & $\mathrm{~J}$ \\
\hline Wheezing & 74.7 & 87.3 & 12.4 & 99.3 & 0.62 \\
Wheezing with dyspnoea & 65.2 & 95.1 & 23.9 & 99.1 & 0.6 \\
Wheezing without cold & 59.8 & 93.6 & 18.2 & 99 & 0.53 \\
Nocturnal chest tightness & 49.3 & 86.4 & 8 & 98.6 & 0.36 \\
Rest dyspnoea & 47.1 & 94.9 & 18 & 98.7 & 0.42 \\
Exercise dyspnoea & 69.3 & 75.7 & 6.4 & 99 & 0.45 \\
Nocturnal dyspnoea & 46.2 & 96 & 21.5 & 98.7 & 0.42 \\
Nocturnal cough & 49.3 & 72.3 & 4.1 & 98.4 & 0.22 \\
Chronic cough & 21.5 & 95.2 & 9.6 & 98.1 & 0.17 \\
Chronic phlegm & 22.7 & 93.3 & 7.5 & 98.1 & 0.16 \\
Chronic bronchitis & 12.5 & 98.2 & 14 & 97.9 & 0.11 \\
\hline
\end{tabular}

S: sensitivity; SP: specificity; PPV: positive predictive value; NPV: negative predictive value; J: Youden index.

wheezing, whatever the form. Wheezing in any form was the most prevalent symptom $(168 / 225 ; 75 \%)$ in asthmatics. All symptoms, except isolated wheezing (W), nocturnal chest tightness, exercise dyspnoea and nocturnal cough, had a specificity of $>90 \%$. Wheezing with dyspnoea and nocturnal dyspnoea had the best positive predictive values $(23.9 \%$ and $21.5 \%$, respectively). The negative predictive value of all the symptoms was higher than $97.9 \%$. The three types of wheezing (table 1) produced the best Youden index.

\section{Selection of individual symptoms to build up symptom combinations}

In step 2, wheezing was present in more than $94 \%$ of asthmatics. The three chronic symptoms (CP,CC and $\mathrm{CB})$ were excluded because of their low prevalence (table 2). Of the asthmatics who did not show any form of wheezing (step 3), nocturnal symptoms (ND, NCT and NC) and exercise dyspnoea were the most frequent symptoms. The three chronic symptoms, expectoration, cough and bronchitis ( $\mathrm{CP}, \mathrm{CC}$ and $\mathrm{CB}$, respectively) were also excluded from the selection of symptoms because of their low prevalence (table 3 ). The remaining symptoms were then systematically combined (step 4), and the diagnostic value of each of the combinations evaluated for the whole cohort.

Table 2. - Prevalence of symptoms in asthmatics (168/ $225 ; 75 \%$ ) who belong to the 51 best combinations of symptoms

\begin{tabular}{lc}
\hline Symptom & Prevalence \% \\
\hline Wheezing & 94.4 \\
Wheezing with dyspnoea & 87.6 \\
Wheezing without cold & 79.8 \\
Exercise dyspnoea & 82 \\
Nocturnal chest tightness & 67.4 \\
Nocturnal dyspnoea & 68.5 \\
Rest dyspnoea & 71.9 \\
Nocturnal cough & 68.5 \\
Chronic phlegm & 43.8 \\
Chronic cough & 42.7 \\
Chronic bronchitis & 24.7 \\
\hline
\end{tabular}

Table 3.-Prevalence of symptoms in nonwheezer asthmatics (57/225; no wheezing, no wheezing with dyspnoea and no wheezing without cold)

\begin{tabular}{lc}
\hline Symptom & Prevalence \% \\
\hline Exercise dyspnoea & 57 \\
Nocturnal cough & 41 \\
Rest dyspnoea & 32 \\
Nocturnal dyspnoea & 30 \\
Nocturnal chest tightness & 30 \\
Chronic chough & 16 \\
Chronic phlegm & 14 \\
Chronic bronchitis & 9 \\
\hline
\end{tabular}

\section{Diagnostic value of symptom combinations}

The diagnostic value of symptoms are presented in table 4 . The best sensitivity $(80 \%)$ was obtained by combining wheezing with two nocturnal symptoms (combination 15). The specificity of all the combinations was higher than $92 \%$ when combination 15 (wheezing associated with 2 nocturnal symptoms) and combination 16 (which includes only the nocturnal symptoms) were excluded. Combining wheezing with rest dyspnoea (combination 2) produced the best PPV. Wheezing accompanied by nocturnal dyspnoea or rest dyspnoea (combinations 4 and 5, respectively) produced a PPV slightly less than $40 \%$. Combination 16 , which combines the three nocturnal symptoms, was particularly mediocre with a specificity of $63.5 \%$ and a PPV of less than 5\%. Combinations 7, 10 and 15 had the best Youden index. All 16 combinations had a similar NPV close to $100 \%$.

\section{Discussion}

Bronchial asthma is one of the most important chronic respiratory diseases with a continuously rising morbidity [12-14]. The costs of asthma are high [15], and it is worthwhile to improve its diagnosis. The prevalence of current asthma in this study was $2.3 \%$. NeUKIRCH et al. [8] found a slightly higher prevalence of current asthma between $2.7 \%$ and $4.0 \%$ depending on the regions they studied (Grenoble and Paris, respectively). A multicentre study from Italy [16] also showed a similarly higher prevalence of asthma between $2.5 \%$ and $3.6 \%$. The principal reason for this difference is due to the authors' more restrictive definition of asthma. To diagnose asthma in this study, subjects had to not only have been previously asthma diagnosed by a physician, but also have suffered from at least one asthma attack within the last 12 months. The aim of this study was not to establish the prevalence of either asthma or its symptoms, though both prevalences were astonishingly similar to those shown in the European Community Respiratory Health Survey (ECRHS) [8, 16, 17] which crossed linguistic barriers. This is not surprising since this study used the same questionnaire as in the ECHRS. There were no significant differences in prevalences between the three speaking areas: French, German and Italian. The authors' aim was to determine how a clinician could use symptoms drawn from simple medical history to better diagnose asthma. The 
Table 4. - Diagnostic value of symptom combinations in the diagnosis of active asthma

\begin{tabular}{|c|c|c|c|c|c|}
\hline Symptom combination & $\mathrm{S} \%$ & $\mathrm{SP} \%$ & $\mathrm{PPV} \%$ & NPV $\%$ & $\mathrm{~J}$ \\
\hline W and NCT & 40.9 & 97.5 & 28.1 & 98.6 & 0.38 \\
\hline W and RD & 38.4 & 98.7 & 42 & 98.5 & 0.37 \\
\hline $\mathrm{W}$ and $\mathrm{ED}$ & 54.2 & 95.7 & 23.1 & 98.9 & 0.5 \\
\hline $\mathrm{W}$ and ND & 37.5 & 98.6 & 39.3 & 98.5 & 0.36 \\
\hline $\mathrm{W}$ and $(\mathrm{RD}$ a/o ND) & 51.3 & 98 & 38.3 & 98.8 & 0.49 \\
\hline $\mathrm{W}$ and (RD a/o ND a/o NCT) & 56.3 & 96.8 & 29.4 & 98.9 & 0.53 \\
\hline $\mathrm{W}$ and (RD a/o ND a/o ED a/o NCT) & 65.2 & 94.5 & 21.9 & 99.1 & 0.6 \\
\hline (W a/o NC) and (RD a/o ND) & 57.8 & 95.8 & 24.8 & 99 & 0.54 \\
\hline (W a/o NC) and (RD a/o ND a/o NCT) & 63.1 & 91.6 & 15.2 & 99 & 0.55 \\
\hline (W a/o NC) and (RD a/o ND a/o ED a/o NCT) & 75.1 & 84.6 & 10.5 & 99.3 & 0.6 \\
\hline (W a/o NCT) and (RD a/o ND a/o NC) & 67.9 & 89.7 & 13.6 & 99.2 & 0.58 \\
\hline (W a/o NCT) and (RD a/o ND) & 58 & 95.6 & 23.8 & 99 & 0.54 \\
\hline (W a/o ND) and NCT & 46.2 & 95.8 & 20.7 & 98.7 & 0.42 \\
\hline (W a/o ND) and RD & 43.6 & 97.9 & 32.9 & 98.6 & 0.41 \\
\hline $\mathrm{W}$ a/o 2 nocturnal symptoms & 80 & 85.9 & 11.9 & 99.4 & 0.66 \\
\hline$(\mathrm{NC}$ a/o ND a/o NCT) & 75.1 & 63.5 & 4.7 & 99.1 & 0.3 \\
\hline
\end{tabular}

S: sensitivity; SP: specificity; PPV: positive predictive value; NPV: negative predictive value; J: Youden index. W: any wheezing; NCT: nocturnal chest tightness; RD: rest dyspnoea; ED: exercise dyspnoea; ND: nocturnal dyspnoea; NC: nocturnal cough; a/o: and/or; nocturnal symptoms: NCT, ND or NC.

participation rate in the study was slightly lower than that in the European Survey. To ensure the quality of the response, the methodology of the ECHRS was followed and only specifically trained staff were used, who entered the data into the computer immediately and in the presence of the subjects.

As shown by TOREN et al. [2], diagnosis of asthma cannot be based exclusively on functional criteria. There are still no gold standard specific markers to diagnose asthma. Bronchial hyperreactivity (BHR) could have been used as a marker in the diagnosis of asthma, as discussed in a previous publication [18]. However, as WoOLCOCK pointed out [19], BHR is not at all specific for asthma. It can be found in patients with other diseases, especially chronic obstructive pulmonary diseases [20] or can be absent in patients with asthmatic symptoms [21, 22], probably indicating episodic asthma. The present authors therefore decided not to use BHR, despite the fact that most of our subjects participated in the methacholine test.

PekKanen and Pearce [23] recently produced a review on the definition of asthma in epidemiological studies. They showed poor agreement between objective laboratory measurements such as BHR and clinical asthma. They suggested that although clinical asthma cannot be considered to be a true gold standard of asthma, it currently represents the most appropriate standard for use in validating instruments for epidemiological studies. JENKINS et al. [24] tried to validate an asthma questionnaire with or without BHR to diagnose asthma. Interestingly, they concluded that adding BHR to an asthma symptom questionnaire would dramatically decrease the sensitivity to detect clinical asthma and miss the majority of asthmatics involved in this epidemiological study. Since there is no gold standard to define asthma, the diagnostic approach was limited to current asthma as confirmed by a medical doctor, as used by BuRRows et al. [7].

In medical practice any physician will make a diagnosis of asthma on a collection of symptoms and not on the basis of an isolated symptom or diagnostic tests such as methacholine challenge. However as far as the authors are concerned, no other study has ever addressed the diagnostic value of combinations of symptoms when making a diagnosis of asthma.

Wheezing, in whatever form, has a high diagnostic value as single symptom, with not only a good sensitivity and a well conserved specificity, but an excellent PPV and was associated with the best Youden index (table 1). The combination of wheezing, in whatever form, associated with two nocturnal symptoms (cough, dyspnoea or chest tightness) had the best Youden index with well conserved sensitivity and specificity (combination 15, table 4); these symptoms can also be seen in combinations 8 and 12 of table 4 .

The results show that it would be advantageous for any clinician to look more systematically for the presence of wheezing when attempting to make a diagnosis of asthma and to ask the patient about nocturnal symptoms. As shown by Gross [25] many years ago, there is no universally accepted definition of asthma. None of the definitions which have been put forward over time [26-31] relate its diagnosis only to respiratory symptoms. There are also pitfalls in epidemiological questionnaires. For example, answers to the various questions on respiratory symptoms depend on many factors: patient's memory and understanding of the questions, over and underreporting of symptoms, etc. will all influence the answers to the questionnaire [29]. The authors have attempted to avoid as many imprecisions as possible: the questionnaire was conducted by a trained technician using a computer to record answers immediately. The SAPALDIA questionnaire is an extended version of the questionnaire used in the European Community Respiratory Health Survey $[1,17]$. Other studies have used the same questionnaire but have not attempted to calculate the sensitivity and specificity of the different symptoms in asthmatics $[8,16]$.

It remains to be seen whether the symptomatic profile found in the present study is coherent with other epidemiological studies on bronchial asthma. Many 
authors have been interested in asthmatic symptoms. Using a questionnaire distributed to 1,444 subjects recruited by medical practitioners around London, LiTTLEJOHNS et al. [32] determined that of 33 diagnosed asthmatics, 94\% suffered from wheezing, 91\% from cough, 94\% from dyspnoea and $89 \%$ from production of phlegm. This last symptom was only present in $22 \%$ of our asthmatics. Nocturnal symptoms are equally frequent. Two studies have shown that more than $90 \%$ of asthmatics are woken up at least once per month by these symptoms [33, 34]. Guidelines of the International Asthma Management Project, 1992 [35] include nocturnal symptoms not only in the diagnosis but in the classification of asthma severity. However the present study showed that isolated nocturnal symptoms are poor predictors of asthma (table 1).

Many authors i.e. refs. [3-5] have confirmed that cough may be the only symptom of asthma, although there are only a few studies published on this topic, with small numbers of subjects, hence questioning whether serious conclusions may be drawn. For general medical practice, the present study allowed identification of more than 200 asthmatics from a cohort of about 10,000 subjects, and showed that nocturnal and chronic cough are neither sensitive nor specific enough to predict the diagnosis of asthma.

Many studies have shown that wheezing is a symptom that is equally frequently found in asthmatics and the general population. DoDGE et al. [36] found that the prevalence of wheezing accompanied by dyspnoea is $10 \%$ and depending on the age group considered, wheezing represents up to $30 \%$ of all respiratory symptoms. They did not examine the diagnostic value of symptoms in asthma. MorTagy et al. [37] found a wheezing prevalence of $27 \%$ in more than 2,200 subjects. PEAT et al. [38], in a study using more than 5,000 subjects, showed a wheezing prevalence of $24.2 \%$ and LitTLEJohns et al. [32] found a prevalence of wheezing of $21 \%(313 / 1,444)$. In the study of NEUKIRCH et al. [8], prevalence of wheezing was $14 \%$ in the general population. It can be concluded from this study that $25 \%$ of asthmatics do not wheeze, and that the prevalence of wheezing in the general population is very similar to previous studies. All these studies underline the importance of wheezing in asthma, but also that it is not necessarily present in this disease.

It is interesting to note that DoDGE et al. [36], using a different statistical approach, found that of 36 newly diagnosed asthmatics, the PPV of the combination of dyspnoea with wheezing, cough and chronic bronchitis was $29 \%$. Neukirch et al. [8] showed that the relative risk of having bronchial asthma is markedly elevated for subjects who suffer from nocturnal dyspnoea or wheezing (associated either with or without dyspnoea).

Medical textbooks describe dyspnoea as a diagnostic symptom of asthma, an observation which is confirmed in the present study, taking a cohort of 225 asthmatics from a normal population. Wheezing accompanied by nocturnal dyspnoea or dyspnoea at rest has a very good diagnostic value (combinations 2, 4 and 5, table 4). One has to be aware that in the combinations drawn from the present study, subjects may show the different symptoms at different times, a fact which must be distinguished from the isolated symptom (WD) where wheezing and dyspnoea were simultaneously present. When combining these two symptoms, PPV almost doubles from $23 \%$ to $40 \%$. The other combinations of symptoms, though more complex, do not improve the diagnostic value of the history and are therefore not very useful in clinical practice for the diagnosis of asthma.

In conclusion, this study showed that wheezing with dyspnoea is the best isolated symptom for the diagnosis of asthma. As for the combinations of symptoms, the association of wheezing with two of the three nocturnal symptoms (nocturnal dyspnoea, chest tightness and cough) is the best anamnestic tool to diagnose asthma. It needs to be emphasised that these results have been obtained from an epidemiological study which may possibly limit its clinical value. However, the data suggest that clinicians should focus on particular combinations of symptoms in the differential diagnosis of asthma prior to confirmation by paraclinical objective tests.

SAPALDIA (Swiss Study on Air Pollution and Lung Diseases in Adults) Team: Study director: P. Leuenberger (p); Program director: U. Ackermann-Liebrich (e); Members: P. Alean (am), K. Blaser (a), G. Bolognini (p), J.P. Bongard (p), O. Brändli (p), P. Braun (p), C. Bron (l), M. Brutsche (1), C. Defila (m), G. Domenighetti (p), S. Elsasser (1), L. Grize (s), P. Guldimann (1), P. Hufschmid (1), W. Karrer (p), H. Keller-Wossidlo (o), R. Keller (p), N. Künzli (e), J.C. Luthy (1), B.W. Martin (e), T. Medici (p), C. Monn (am), A.G. Peeters (pa), A.P. Perruchoud (p), A. Radaelli (1), C. Schindler (s), J. Schwartz (s), G. Solari (p), M. Schöni (p), J.M. Tschopp (p), P. Villiger (p), B. Wüthrich (a), J.P. Zellweger (p), E. Zemp (e). (a): allergology, (am): air pollution monitoring, (e): epidemiology, (1): local assistant (MD), (m): meteorology, (o): occupational medecine, (p): pneumology, (pa): pathology, (s): statistics.

\section{References}

1. Wüthrich B, Schindler C, Leuenberger P, AckermannLiebrich U, SAPALDIA-Team. Prevalence of atopy and pollinosis in the adult population of Switzerland. Int Arch Allergy Immunol 1995; 106: 149-156.

2. Toren K, Brisman J, Jarvholen B. Asthma and asthma-like symptoms in adults assessed by questionnaires. Chest 1993; 104: 600-608.

3. O'Connell E, Rojas AR, Sachs MI. Cough-type asthma: a review. Ann Allergy 1991; 66: 278-286.

4. Corrao WM, Braman SS, Irwin RS. Chronic cough as the sole presenting manifestation of bronchial asthma. $N$ Engl J Med 1979; 300: 633-637.

5. Koh YY, Chae A, Min KU. Cough variant asthma is associated with a higher wheezing threshold than classic asthma. Clin Exp Allergy 1993; 23: 696-701.

6. Baumann UA, Haerdi E, Keller R. Relations between clinical signs and lung function in bronchial asthma: How is acute bronchial obstruction reflected in dyspnea and wheezing? Respiration 1986; 50: $294-300$.

7. Burrows B, Lebowitz MD, Barbee RA, Cline MG. Findings before diagnoses of asthma among the elderly in a longitudinal study of a general 
population sample. J Allergy Clin Immunol 1991; 88: $870-877$.

8. Neukirch F, Pin I, Knani J, et al. Prevalence of asthma and asthma-like symptoms in three French cities. Respir Med 1995; 89: 685-692.

9. Martin BW, Ackermann-Liebrich U, Leuenberger P, et al. SAPALDIA: Methods and participation in the cross-sectional part of the Swiss Study on Air Pollution and Lung Diseases in Adults. SozPräventivmed 1997; 42: 67-84.

10. Grenier B. Décision médicale. Paris: Masson, 1993.

11. Weinstein MC, Fineberg HV, Elstein AS, et al. Clinical Decision Analysis. Philadelphia: W.B. Saunders Company, 1980.

12. Nicklas RA. Perspective on asthma mortality - 1989. Ann Allergy 1989; 63: 578-584.

13. Campbell S, Hood I, Ryan D, Biedrzycki L, Mirchandani H. Death as result of asthma in Wayne county medical examiner cases, $1975-1987$. J Forensic Sci 1990; 35: 356-364.

14. Weiss KB, Wagner DK. Changing patterns of asthma mortality. JAMA 1990; 264: 1683-1687.

15. Barnes PJ, Jonsson B, Klim JB. The costs of asthma. Eur Respir J 1996; 9: 636-642.

16. European Community Respiratory Health Survey Italy. Prevalence of asthma and asthma symptoms in a general population sample from northern Italy. Allergy 1995; 50: 755-759.

17. Bumey PGJ, Luczynsca C, Chinn S, Jarvis D. The European Community Respiratory Health Survey. Eur Respir J 1994; 7: 954-960.

18. Tschopp JM, Sistek D, Schindler C, et al. and SALPADIA-team. Current allergic asthma and rhinitis: diagnostic efficiency of three commonly used atopic markers (total Ig E, skin prick tests and Phadiatop (B). Allergy 1998; 53: $608-613$.

19. Woolcock AJ. Asthma. In: Murray J, Nadel J, eds. Respiratory Medicine. Philadelphia, W.B. Saunders Company, 1994; 1289.

20. Yan K, Salome CM, Woolcock AJ. Prevalence and nature of bronchial hyperreponsiveness in subjects with chronic obstructive pulmonary disease. Am Rev Respir Dis 1985; 132: 25-29.

21. Stanescu DC, Frans A. Bronchial asthma without increased airway reactivity. Eur J Respir Dis 1982; 63: $5-12$.

22. Woolcock AJ, Barnes PJ. Epidemiology of asthma. Am Rev Respir Dis 1992; 147: 1358-1359.

23. Pekkanen J, Pearce N. Defining asthma in epidemiological studies. Eur Respir J 1999; 14: 951 957.
24. Jenkins $\mathrm{M}$, Clarke $\mathrm{J}$, Carlin $\mathrm{J}$, et al. Validation of questionnaire and bronchial hyperresponsiveness against respiratory physician assessment in the diagnosis of asthma. Int J Epidemiol 1996; 25: 609 616.

25. Gross NJ. What is this thing called love? - Or defining asthma. Am Rev Respir Dis 1980; 121: 202-203.

26. American Thoracic Society. Standards for the diagnosis and care of patients with chronic obstructive pulmonary disease and asthma. Am Rev Respir Dis 1987; 136: 225 - 244.

27. Burney PGJ, Chinn S, Britton JR, Tattersfield AE, Papacosta AO. What symptoms predict the bronchial response to histamine? Evaluation in a community survey of the bronchial symptoms questionnaire (1984) of The International Union Against Tuberculosis and Lung Disease. Int J Epidemiol 1989; 18: 165-173.

28. Teculescu D. Définitions claires des bronchopneumopathies chroniques. $J$ Radiol 1991; 72: 375-379.

29. Toelle BG, Peat JK, Salome CM, Mellis CM, Woolcock AJ. Toward a definition of asthma for epidemiology. Am Rev Respir Dis 1992; 146: 633-637.

30. Scadding JG. Definition and clinical categories of asthma. In: Clark TJH, Godfrey S, eds. Asthma. London, Chapman and Hall, 1985; $120-143$.

31. Woolcock AJ. Epidemiologic methods for measuring prevalence of asthma. Chest 1987; 91S: 89S-92S.

32. Littlejohns P, Ebrahim S, Anderson R. Prevalence and diagnosis of chronic respiratory symptoms in adults. BMJ 1989; 298: $1556-1560$.

33. Fitzpatrick MF, Martin K, Fossa E, Shapiro C, Elton RA, Douglas NJ. Snoring, asthma and sleep disturbance in Britain: a community based survey. Eur Respir J 1993; 6: 531-535.

34. Turner-Warwick M. Nocturnal asthma: a study in general practice. J R Coll Gen Pract 1989; 39: 230 242.

35. National Heart Lung and Blood Institute. International consensus report on diagnosis and treatment of asthma. Eur Respir J 1992; 5: 601-641.

36. Dodge R, Burrows B, Lebowitz MD, Cline MG. Antecedent features of children in whom asthma develops during the second decade of life. J Allergy Clin Immunol 1993; 92: 744-749.

37. Mortagy AK, Howell JBL, Waters WE. Respiratory symptoms and bronchial reactivity: identification of a syndrome and its relation to asthma. BMJ 1986; 293 : 525-529.

38. Peat J, Haby M, Spijker J, Berry G, Woolcock AJ. Prevalence of asthma in adults in Busselton, Western Australia. BMJ 1992; 305: 1326-1329. 